\title{
The ionospheric signature of transient dayside reconnection and the associated pulsed convection return flow
}

\author{
S. E. Milan ${ }^{1}$, M. Lester ${ }^{1}$, R. A. Greenwald ${ }^{2}$, G. Sofko ${ }^{3}$ \\ ${ }^{1}$ Department of Physics and Astronomy, University of Leicester, Leicester LE1 7RH, UK \\ ${ }^{2}$ Johns Hopkins University, Applied Physics Laboratory, Maryland, USA \\ ${ }^{3}$ University of Saskatchewan, Saskatchewan, Canada
}

Received: 26 October 1998 / Revised: 28 April 1999 / Accepted: 4 May 1999

\begin{abstract}
Three SuperDARN coherent HF radars are employed to investigate the excitation of convection in the dayside high-latitude ionosphere in response to transient reconnection occurring in the cusp region. This study demonstrates the existence of transient antisunward-propagating backscatter features at the expected location of the ionospheric footprint of the cusp region, which have a repetition rate near $10 \mathrm{~min}$. These are interpreted as the ionospheric signature of flux transfer events. Moreover, transient sunward-propagating regions of backscatter are observed in the convection return flow regions of both the pre- and post-noon sectors. These patches are observed to propagate towards the noon sector from at least as far around the auroral zone as 07 MLT in the pre-noon sector and 17 MLT in the post-noon sector, travelling with a velocity of approximately 1.5 to $2 \mathrm{~km} \mathrm{~s}^{-1}$. These return flow patches have a repetition rate similar to that of the transient features observed at local noon. While providing supporting evidence for the impulsive nature of convection flow, the observation of sunward-propagating features in the return flow region is not consistent with current conceptual models of the excitation of convection.
\end{abstract}

Key words. Ionosphere (plasma convection) - Magnetospheric physics (magnetopause, cusp, and boundary layers; magnetosphere-ionosphere interactions)

\section{Introduction}

Ionospheric convection is generally accepted to be excited, at least in part, by magnetic reconnection occurring on the dayside at or near the subsolar

Correspondence to: $\mathrm{S}$. E. Milan magnetopause, mapping to the cusp region, and on the nightside within the magnetotail, associated with substorm processes. The cusp region (see the review papers of Lockwood, 1991, and Smith and Lockwood, 1996, and references therein) and the excitation of dayside convection is the focus of the present study. While the relative importance of quasi-continuous reconnection and more transient and intermittent "flux transfer events" (FTEs) (Russell and Elphic, 1978) is as yet unclear, there is a considerable body of evidence to suggest that the auroral signature of the cusp, related to the entry of magnetosheath plasma into the magnetosphere, and the ionospheric plasma flow at the footprint of the cusp are pulsed (e.g. Fasel et al., 1992; Lockwood et al., 1993). Conceptual models of the convection response to transient reconnection (e.g. Southwood, 1987; Cowley and Lockwood, 1992; Cowley et al., 1992) suggest that with each burst of reconnection, or FTE, a region of newly opened magnetic flux is appended onto the front of the polar cap, at the ionospheric footprint of the merging line. In the Southwood (1987) model, the resultant motion of the newly opened flux tube under the stresses applied to it by the IMF and magnetosheath flow, cause displacement of the open or closed incompressible field lines around it. In an alternative picture (Cowley and Lockwood, 1992; Cowley et al., 1992), following the creation of new open flux, the open/closed field line boundary (OCFLB) or the polar cap boundary is now perturbed from its "zero-flow equilibrium" position, conceptually conceived as circular. Flows are excited, initially within the newly opened field line region, and subsequently over the entire polar cap, to return the system to equilibrium. Along the OCFLB of the region of newly opened flux, the flows have a poleward component, and elsewhere along the OCFLB the flows have an equatorward component, and the flow within the polar cap is generally antisunward. The resulting displacement of the closed field lines equatorward of the OCFLB leads to sunward plasma drift in the convection return flow region. It is conjectured, then, that a twin-vortical flow pattern, comprising plasma 
drift velocities of the order of several $100 \mathrm{~m} \mathrm{~s}^{-1}$, is generated at noon and expands poleward across the polar cap and azimuthally around the polar cap boundary with a phase speed of a few $\mathrm{km} \mathrm{s}^{-1}$ (Cowley et al., 1992); in general, a pre-/post-noon asymmetry is introduced by the $B_{y}$ component of the IMF, though this is not relevant to the present discussion. The time scale of the excitation and subsequent decay of the largescale flow pattern associated with an individual FTE is estimated to be of the order of 10 to $15 \mathrm{~min}$. The timeaveraged flow excited by a sequence of FTEs, recurring at their mean repetition rate of $8 \mathrm{~min}$ (e.g. Bercham and Russell, 1984), together with reconnection occurring on the nightside, recreates the traditional twin-cell convection pattern. It must be emphasised, however, that within this conceptual framework the excitation of convection is a consequence of the displacement of the pre-existing open flux of the polar cap by the much smaller region of newly opened flux created by reconnection; as the ratio of areas of the new and old open flux regions is of the order of 0.03 (Lockwood et al., 1990), then the plasma displacement in response to an individual FTE should be small, especially away from the ionospheric footprint of the cusp.

Previously, most studies have focused on the excitation of convection flow at the ionospheric footprint of the cusp, and less attention has been paid to the excitation of sunward flow at lower latitudes, on closed field lines, in the convection return flow region. There have been suggestions that this return flow is pulsed in response to transient antisunward flow within the polar cap (Moen et al., 1995, 1996; Provan et al., 1998), though these studies have been confined to measurements along a meridian and hence little information regarding the azimuthal evolution of the flow has been gathered. The present study reports on measurements of the plasma drift over a significant proportion of the dayside high-latitude ionosphere, made by three of the SuperDARN coherent HF radars. Sunward-propagating patches of backscatter are observed in both the preand post-noon sector return flow regions, their motion being tracked across at least $2 \mathrm{~h}$ of MLT in their 8 to 10 min lifetimes. These observations have repercussions for the conceptual models of convection excitation discussed above.

\section{Observations}

Three radars of the SuperDARN network (Greenwald et al., 1995), Saskatoon, Goose Bay, and Pykkvibaer, have been employed in the present study. Each radar completes a 16 beam, 75 range gate, azimuthal scan every $2 \mathrm{~min}$. During the period of the present study, 1330 UT to 1600 UT, 17 April 1996, the Goose Bay radar was observing the noon sector auroral zone and the Saskatoon and Pykkvibaer radars were observing the pre- and post-noon sector auroral zones, respectively. At this time, the IMP-8 spacecraft was located some $15 R_{e}$ upstream of the Earth's bowshock. The spacecraft observed a southward turning of the IMF, to approx- imately $B_{z} \approx-4 \mathrm{nT}$, at $1347 \mathrm{UT}$; the IMF remained southward for several hours following this, except for a brief excursion to $B_{z} \approx 0 \mathrm{nT}$ at $1425 \mathrm{UT}$. Throughout this interval IMF $B_{y}$ was negative, though small, varying between $-1 \mathrm{nT}$ and $-3 \mathrm{nT}$.

At 1350 UT, almost immediately after the southward turning of the IMF was observed at IMP-8, backscatter suddenly appeared within the fields-of-view of the three SuperDARN radars. Range-time-velocity plots for the three radars during the interval 1330 UT to 1600 UT are illustrated in Fig. 1. In these and subsequent plots, positive (negative) velocities correspond to plasma drift toward (away from) the radar. Grey regions are attributed to ground backscatter and are of no interest to the study. Moreover, the band of scatter at magnetic latitudes below $70^{\circ}$ within the Pykkvibaer field-of-view originate in the $\mathrm{E}$ region and will not be discussed further. In all three cases, the observations of interest take the form of regions of backscatter which appear to propagate towards the radar, as in the case of Pykkvibaer, or away from the radar, as in the cases of Goose Bay and Saskatoon. In each of these cases, the plasma drift within the patches is also towards or away from the radars in the same sense. The occurrence of each of these backscatter patches is indicated by arrows. These patches have a mean recurrence period and lifetime of approximately $10 \mathrm{~min}$. The backscatter power associated with these patches is between $10 \mathrm{~dB}$ and $30 \mathrm{~dB}$ above the background noise.

To better understand the nature of these backscatter regions, the clearest example from each radar is examined in more detail. In Fig. 2, a time series of spatial scans from each of the three radars is illustrated, in magnetic latitude and MLT coordinates; in each case the spatial plots are separated by between 2 and $6 \mathrm{~min}$, and the duration of each time series is 8 to $12 \mathrm{~min}$, comparable with the lifetime and recurrence period of the events described already. It is found that the observations from Pykkvibaer and Saskatoon are similar, while those of Goose Bay are different, and this example will be described first. In the first panel, 1448 UT, two regions of backscatter are observed. In the post-noon sector, between $70^{\circ}$ and $75^{\circ}$ magnetic latitude, a region of backscatter with a plasma drift line-ofsight velocity component towards the radar is present; this region of backscatter is thought to correspond to westward convection return flow. In the noon sector, between $76^{\circ}$ and $80^{\circ}$ magnetic latitude, a region of backscatter with plasma drift away from the radar is observed; this region is thought to correspond to the ionospheric footprint of the cusp, as will be discussed later. By 1452 UT this region has expanded both equatorward and poleward by $1^{\circ}$ or $2^{\circ}$ of latitude. In the following two panels, 1456 UT and 1458 UT, the region continues to expand poleward, though the poleward portion of the backscatter breaks away from the equatorward portion, and then fades; it is possible that the poleward-progressing region of backscatter has a tendency to drift toward the post-noon sector. At this time, the equatorward boundary of the region is once more retreating poleward, towards its initial position. 


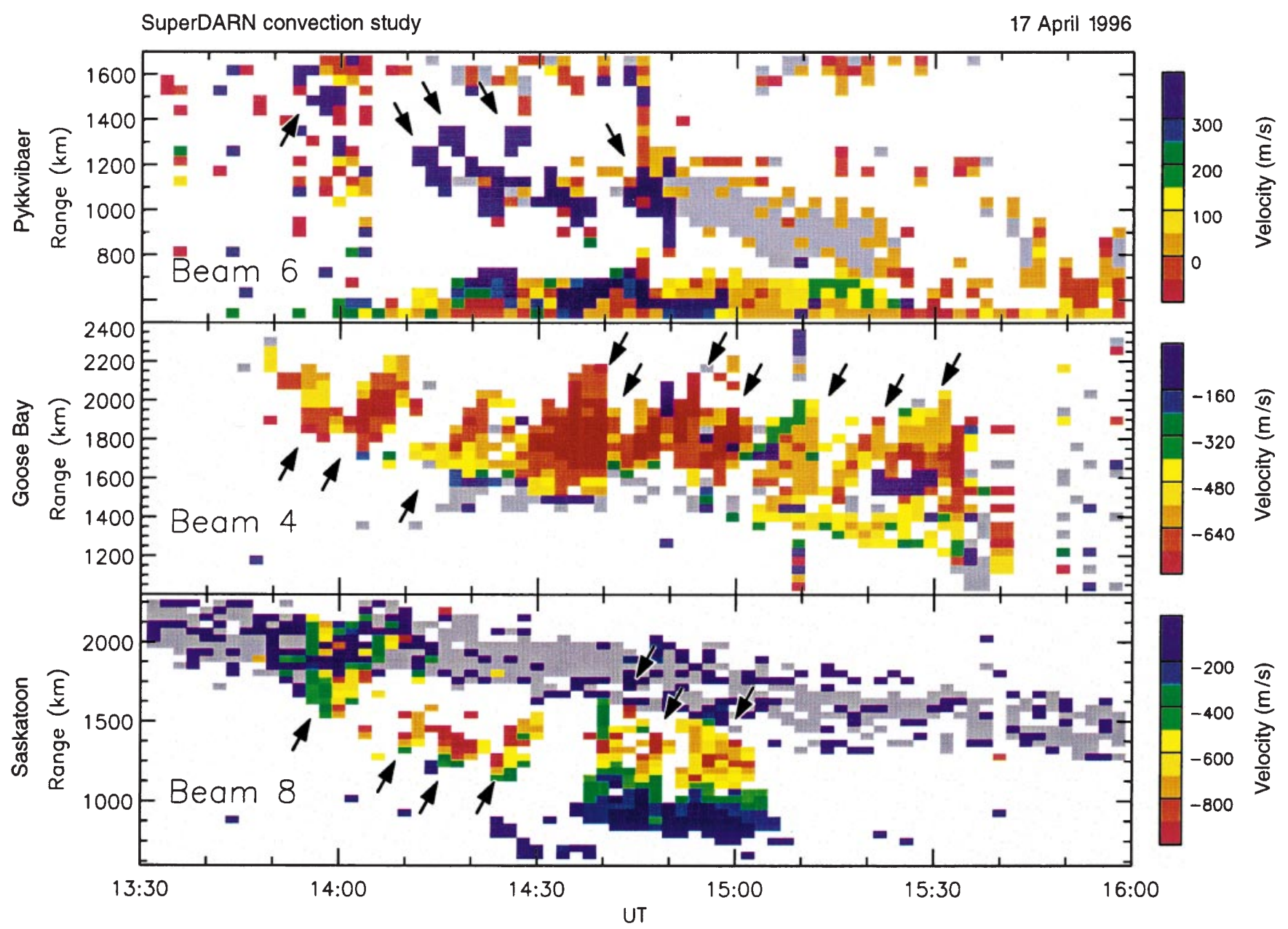

Fig. 1. Range-time-velocity plots for the Saskatoon, Goose Bay and Pykkvibaer radars between 1330 UT and 1600 UT, on 17 April, 1996. Arrows in the Goose Bay radar panel indicate the occurrence of FTE

By 1500 UT (not shown), this region of backscatter has returned to its original configuration. Over the $10 \mathrm{~min}$ cycle, this region expands poleward by some $400 \mathrm{~km}$ before fading, corresponding to a velocity of $650 \mathrm{~m} \mathrm{~s}^{-1}$, commensurate with the line-of-sight component of the plasma drift velocity measured within the region.

Within the Pykkvibaer radar field-of-view, at 1438 UT, a patch of backscatter with a plasma drift velocity over $1 \mathrm{~km} \mathrm{~s}^{-1}$ is observed between 16 and 17 MLT, at a magnetic latitude near $68^{\circ}$ (indicated by arrow). Lower velocity backscatter is attributed to ground or E region backscatter. In the following three panels the high plasma drift velocity patch of backscatter (indicated by arrows in each panel) moves westward (sunward), before drifting out of the field-of-view at 15 MLT after 1450 UT. A similar feature is observed within the Saskatoon field-of-view, in which a patch of backscatter initially observed near 07 MLT drifts eastward (sunward) before last being seen near 09 MLT at 1432 UT. This patch of backscatter is associated with plasma drift velocities up to $2 \mathrm{~km} \mathrm{~s}^{-1}$. In both of these cases, the patches of backscatter progressed through some $2 \mathrm{~h}$ of MLT in $10 \mathrm{~min}$, which at a latitude near $70^{\circ}$ is a velocity signatures; arrows in the Saskatoon and Pykkvibaer radar panels indicate the occurrence of return flow backscatter patches

of approximately between 1.5 and $2 \mathrm{~km} \mathrm{~s}^{-1}$. The direction of plasma drift within these patches is consistent with sunward flow within the convection return flow region.

\section{Discussion}

Following a southward turning of the IMF, backscatter is generated within the viewing areas of three coherent HF radars located in the pre-noon, noon, and post-noon sectors of the high-latitude ionosphere. At local noon, the expected location of the ionospheric footprint of the cusp as the $B_{y}$ component of the IMF is small, poleward-propagating regions of poleward flow are observed. Similar poleward-moving backscatter forms have previously been interpreted as the ionospheric signature of flux transfer events (Pinnock et al., 1995), and indeed the event repetition rate is consistent with that of FTEs (Bercham and Russell, 1984). The spatial observations of these forms bear many similarities to the Cowley et al. (1992) conceptual model of the ionospheric response to transient reconnection: the most recently 

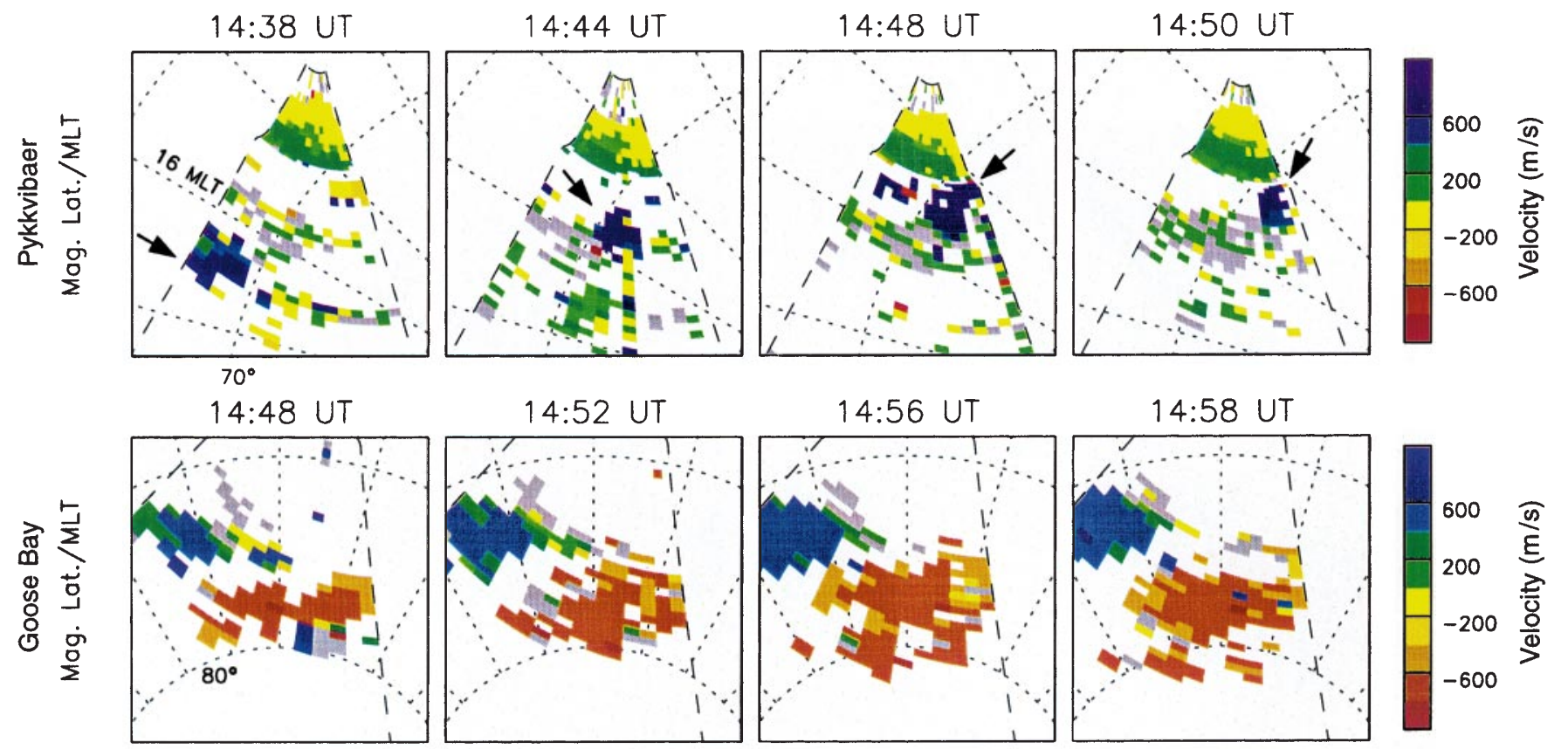

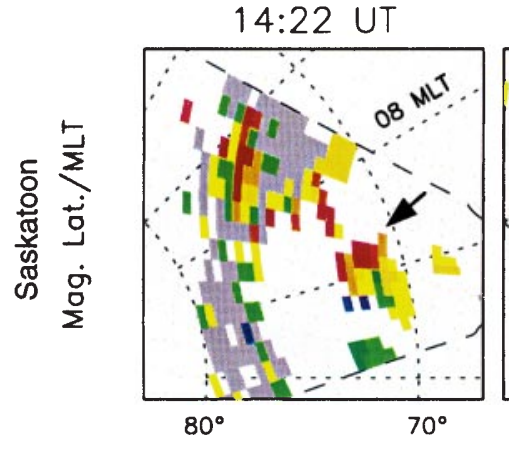

Fig. 2. Time series of two-minute scan spatial maps of line-of-sight plasma drift velocity for the three radars in magnetic latitude and MLT coordinates; magnetic local noon (12 MLT) is towards the top of the page, radial dotted lines indicate MLT meridians and curved dotted lines represent $60^{\circ}, 70^{\circ}$, or $80^{\circ}$ magnetic latitude. Dashed lines indicate the extent of the radar fields-of-view. In the Pykkvibaer and Saskatoon radar panels, arrows indicate the location of the return flow backscatter patches created region of open flux, visible through the precipitation of magnetosheath particles into the ionosphere, is displaced poleward by the addition of a new region of open flux at its equatorward boundary; the older region of flux subsequently fades from view as its population of magnetosheath particles is finally exhausted. The velocity of the poleward motion of the region of backscatter and the plasma drift velocity within this region are equal, as predicted by the model. Also, the addition of the new region of open flux is first observed as an equatorward step of the low latitude boundary of the cusp backscatter (a proxy for the open/closed field line boundary, or merging line when reconnection is ongoing), which thereafter progresses poleward as the polar cap boundary relaxes to its zero-flow equilibrium position; similar observations of equatorward steps and poleward relaxations of the low latitude boundary of radar backscatter have been presented by Milan et al. (1999), who demonstrated that this occurred in tandem with identical motions of the red line optical aurora associated with the cusp region. The tendency for regions of newly opened flux to drift into the post-noon sector is consistent with the (small) negative component of IMF $B_{y}$. Interestingly, the ionospheric plasma drift velocity associated with the cusp region remains approximately uniform throughout and between each cycle, suggestive of inductive smoothing of the convection response to transient reconnection as proposed by Lockwood and Cowley (1992). Due to the equatorward progression and subsequent poleward retreat of the open/closed field line boundary, the plasma drift across this boundary is not constant; in fact, it is estimated that this relative velocity is of the order of $1 \mathrm{~km} \mathrm{~s}^{-1}$ during the equatorward motion of the OCFLB (during merging) and $0 \mathrm{~km} \mathrm{~s}^{-1}$ during the poleward motion of the OCFLB (when the OCFLB is "adiaroic", see Siscoe and Huang, 1985). However, averaged over the 10 min FTE cycle, the plasma drift relative to the OCFLB is $650 \mathrm{~m} \mathrm{~s}^{-1}$, corresponding to a mean reconnection electric field of $32 \mathrm{mV} \mathrm{m}^{-1}$. If the region of cusp 
backscatter represents the full width of the ionospheric footprint of the merging gap, then this is calculated to be $1300 \mathrm{~km}$ in length, giving an estimate of the mean contribution of FTEs to the cross polar cap potential of $42 \mathrm{kV}$, consistent with the dayside merging rate determined by Baker et al. (1997).

In the pre- and post-noon convection return flow regions, sunward-moving patches of backscatter with sunward plasma drift velocities are observed. These patches have a repetition rate similar to that of the FTE signatures observed in the cusp region, and hence would appear to be generated in response to transient dayside reconnection; that the return flow pulses appear after the southward turning of the IMF and the appearance of FTE signatures, suggests that they are not a response to nightside processes. It has not been possible however, to positively identify a one-to-one correlation between FTE occurrence and the observation of return flow patches; it is not clear whether the patches precede FTE occurrence, occur simultaneously with FTEs, or are a delayed response to FTE occurrence. What, then, is the generating mechanism of these patches of backscatter? Unfortunately, the HF radar technique allows the plasma drift velocity to be measured only within regions of backscatter, regions of the ionosphere containing decametre field-aligned electron density perturbations or irregularities, the targets from which HF radars scatter (see Milan et al., 1998 for a more detailed discussion), and hence the plasma drift within the surrounding ionosphere is unknown. Consequently, in the present case it cannot be determined if the backscatter patches represent a region of ionospheric irregularity generation which drifts with the background convection flow or if the irregularity generation is associated with an enhancement of the convection flow. However, more extensive observations of other pulsed return flow events (the subject of a forthcoming study) allow a more detailed analysis of the flow evolution associated with these patches to be made, and support the second of these possibilities. Such measurements suggest that these backscatter patches are associated with recurrent transient enhancements of the return flow velocity, which are highly periodic in nature. These velocity enhancements propagate sunward from the dawn and dusk sectors toward local noon. These observations bear some similarities to previous observations of sunward-propagating ULF waves located on or near the magnetopause (Sofko et al., 1979; Nielsen, 1984). Irrespective of the exact nature of these return flow transients, they would appear to be closely related to dayside reconnection and convection processes.

These observations suggest that transient dayside reconnection can play a major role in the excitation of ionospheric convection. Poleward-propagating regions of backscatter observed at the expected location of the ionospheric footprint of the cusp are identified with the occurrence of FTEs. In addition, sunward-propagating regions of backscatter associated with transient velocity enhancements are observed within the convection return flow. Both the cusp observations and the existence of return flow velocity enhancements are predicted by the current conceptual models of the convection response to transient dayside reconnection. However, these models would suggest that the phase propagation of the return flow velocity enhancement should be antisunward, either co-located with the advancing front of the enlarging twin-cell convection pattern (Cowley et al., 1992), or due to the displacement of closed field lines equatorward of the antisunward-propagating newlyopened flux tube (e.g., Southwood, 1987). Such situations were discussed by Moen et al. (1996) in relation to their observations of pulsed return flow. In their study, Moen et al. (1996) were unable to distinguish the direction of phase propagation of the velocity enhancement, as their experiment was limited to essentially point-measurements of the convection flow, and surmised that it was antisunward for consistency with theoretical predictions. The present study, however, indicates that the velocity enhancement propagates sunward. It should be noted that the propagation speed of the velocity enhancement appears somewhat slower than the several $\mathrm{km} \mathrm{s}^{-1}$ predicted for the magnetosonic phase propagation of an expansion of the convection pattern.

The findings of the present study raise questions as to the validity of current models of magnetosphere/ionosphere convection. Convection flow does appear to be excited in response to transient dayside reconnection, and the flows over a large portion of the high latitude ionosphere are pulsed at a similar repetition rate to that of flux transfer events. However, the propagation of the convection impulse through the magnetosphere/ionosphere system, causing large-scale flow in response to a localised driving mechanism, has yet to be fully understood.

Acknowledgements. CUTLASS is supported by the Particle Physics and Astronomy Research Council, UK (PPARC grant PPA/R/ R/1997/00256), the Swedish Institute for Space Physics, Uppsala, and the Finnish Meteorological Institute, Helsinki. The authors would like to thank the principle investigator, R. Lepping, for the use of key parameters from the IMP-8 MFI instrument. SEM is supported on PPARC grant PPA/G/0/1997/000254.

Topical Editor D. Alcaydé thanks J. Moen and Gang Lu for their help in evaluating this paper.

\section{References}

Baker, K. B., A. S. Rodger, and G. Lu, HF-radar observations of the dayside magnetic merging rate: a geospace environment modeling boundary layer campaign study, J. Geophys. Res., 102, 9603-9617, 1997.

Berchem, J., and C. T. Russell, Flux transfer events on the magnetopause: Spatial distribution and controlling factors, J. Geophys. Res., 89, 6689, 1984.

Cowley, S. W. H., and M. Lockwood, Excitation and decay of solar wind-driven flows in the magnetosphere-ionosphere system, Annales Geophysicae, 10, 103-115, 1992.

Cowley, S. W. H., J. P. Morelli, M. P. Freeman, M. Lockwood, and M. F. Smith, Excitation and decay of flows in the magnetosphere-ionosphere system due to magnetic reconnection and the dayside magnetopause and in the magnetotail, Proc. Ist International Conference on Substorms (ICS-1), Kiruna, Sweden, March 1992 (ESA SP-335), 117-123, 1992. 
Fasel, G. J., J. I. Minow, R. W. Smith, C. S. Deehr, and L. C. Lee, Multiple brightenings of transient dayside auroral forms during oval expansions, Geophys. Res. Lett., 19, 2429, 1992.

Greenwald, R. A., K. B. Baker, J. R. Dudeney, M. Pinnock, T. B. Jones, E. C. Thomas, J.-P. Villain, J.-C. Cerisier, C. Senior, C. Hanuise, R. D. Hunsucker, G. Sofko, J. Koehler, E. Nielsen, R. Pellinen, A. D. M. Walker, N. Sato, and H. Yamagishi, DARN/ SuperDARN: a global view of the dynamics of high-latitude convection, Space Sci. Rev., 71, 761-796, 1995.

Lockwood, M., The excitation of ionospheric convection, J. Atmos. Terr. Phys., 53, 177-199, 1991.

Lockwood, M., and S. W. H. Cowley, Ionospheric convection and the substorm cycle, Proc. Ist International Conference on Substorms (ICS-1), Kiruna, Sweden, March 1992 (ESA SP-335), 99-110, 1992.

Lockwood, M., S. W. H. Cowley, and M. P. Freeman, The excitation of plasma convection in the high-latitude ionosphere, J. Geophys. Res., 95, 7961-7972, 1990.

Lockwood, M., J. Moen, S. W. H. Cowley, A. D. Farmer, U. P. Løvhaug, H. Lühr, and V. N. Davda, Variability of dayside convection and motions of the cusp/cleft aurora, Geophys. Res. Lett., 20, 1011, 1993.

Milan, S. E., T. K. Yeoman, and M. Lester, The dayside auroral zone as a hard target for coherent HF radars, Geophys. Res. Lett., 25, 3717-3720, 1998

Milan, S. E., M. Lester, S. W. H. Cowley, J. Moen, P. E. Sandholt, and C. J. Owen, Meridian-scanning photometer, coherent HF radar, and magnetometer observations of the cusp: a case study, Annales Geophysicae, 17, 159-172, 1999.
Moen, J., P. E. Sandholt, M. Lockwood, W. F. Denig, U. P. Løvhaug, B. Lybekk, A. Egeland, D. Opsvik, and E. FriisChristensen, Events of enhanced convection and related dayside auroral activity, J. Geophys. Res., 100, 23 917-23 934, 1995.

Moen, J., M. Lockwood, P. E. Sandholt, U. P. Løvhaug, W. F. Denig, A. P. van Eyken, and A. Egeland, Variability of dayside high-latitude convection associated with a sequence of auroral transients, J. Atmos. Terr. Phys., 58, 85-96, 1996.

Nielsen, E., Observations of sunward propagating waves on the magnetopause, J. Geophys. Res., 89, 9095-9099, 1984.

Pinnock, M., A. S. Rodger, J. R. Dudeney, F. Rich, and K. B. Baker, High spatial and temporal resolution observations of the ionospheric cusps, Annales Geophysicae, 13, 919-925, 1995.

Provan, G., T. K. Yeoman, and S. E. Milan, CUTLASS Finland radar observations of the ionospheric signatures of flux transfer events and the resulting plasma flows, Annales Geophysicae, 16, 1411-1422, 1998.

Russell, C. T., and R. C. Elphic, Initial ISEE magnetometer results: magnetopause observations, Space Sci. Rev., 22, 681, 1978.

Siscoe, G. L., and T. S. Huang, Polar cap inflation and deflation, J. Geophys. Res., 90, 543, 1985.

Smith, M. F., and M. Lockwood, Earth's magnetospheric cusps, Rev. Geophys., 34, 233-260, 1996.

Sofko, G. J., R. A. Greenwald, A. Korth, and G. Kresmer, STARE ionospheric electron flows during the August 28/78 GEOS 2 magnetopause crossing, Proc. Sydney Chapman Conference on Magnetopause Boundary Layers, Alpbach, Austria, 1979.

Southwood, D. J., The ionospheric signature of flux transfer events, J. Geophys. Res., 92, 3207-3213, 1987. 